\title{
Novel Edge Fed Planar Inverted F Antenna (PIFA) for LTE High Band Applications
}

\author{
Atipriya Sharma*, Rajesh Khanna and Naveen Kumar \\ ECED, Thapar University, Patiala - 147004, Punjab, India; \\ piyassharma29@gmail.com,rkhanna@thapar.edu,naveen.kumar@thapar.edu
}

\begin{abstract}
In this paper an edge fed planar inverted $\mathrm{F}$ antenna (PIFA) for LTE high band applications. The proposed antenna covers wider bandwidth from $2.78 \mathrm{GHz}$ to $3.94 \mathrm{GHz}$. Edge feed mechanism is used in the proposed structure by which wider bandwidth is achieved. The dimension of patch is $14 \times 16 \mathrm{~mm}^{2}$ and of ground plane is $36 \times 16 \mathrm{~mm}^{2}$. The dimension of patch, shorting plate, feeding plate are optimized using CST software to get optimum results and is presented in this paper. As this antenna is very compact in profile, has good performance, low cost and light weight, due to all these advantages it is suitable and can be easily incorporated as an internal antenna in mobile phones and in other portable device.
\end{abstract}

Keywords: Compact Profile, Edge Feed, High Band, LTE, PIFA

\section{Introduction}

LTE high band is latest technology in $4 \mathrm{G}$ and it has been in use since last couple of years. Now a days the basic need of communication is higher demand of data rate as well as higher speed, which gave the motivation to the growth of the Long Term Evolution (LTE) and LTE advance ${ }^{z}$. LTE advance performance is much better than older $3 \mathrm{G}$ system ${ }^{6}$. IT is also known as $4 \mathrm{G}$ technique. In $4 \mathrm{G}$ many antenna can be used like advance dipole antenna, microstrip antenna, printed antenna and PIFA antenna and many more. The basic requirement of antenna that it should be compact in size low weight so that the size of wireless device can be miniaturized.

For this the first solution was a monopole $\lambda / 2$ antenna $^{-8}$ which was soon replaced by PIFAs. Because monopole antennas have many disadvantages, like unable to resonate at multi-frequencies, protruding structure ${ }^{9}$. There are many other types of antennas are also used like fractal antenna and microstrip patch antenna, but all have different disadvantages $\frac{9,10}{}$. On the other hand PIFA has numerous advantages over the other antenna like easy fabrication, low SAR and easy feeding $\frac{1,2}{}$. For the future technology PIFA is a best antenna due to it is robust structure. PIFA antenna is used as internal antenna in mobile handset as it is very compact in nature ${ }^{3}$. But PIFA has a major disadvantage that is its bandwidth is narrow $^{5}$, due to this it is difficult to have multiband/wideband operation. So researchers are analyzing, designing and proposing various techniques by which PIFA can operate at wideband.

In this paper a compact size edge fed planar inverted $\mathrm{F}$ antenna for high band LTE applications (PIFA) is designed by optimizing the size of patch, feeding plate and shorting plate. The main aim is to design a new PIFA structure that which can work on LTE high band and higher bandwidth is obtained by providing edge feed and by optimizing the dimension of all parameters of an antenna. The structure of antenna should be compact so that it can be easily adjusted in small space.

\section{Antenna Design}

After study the dimensions of different parameters, finally the optimum dimensions of an antenna is proposed. The dimension of the ground plane is $36 \times 16 \mathrm{~mm}^{2}$ and the dimension of patch is $14 \times 16 \mathrm{~mm}^{2}$. The dimension of shorting plate is $6.035 \times 2 \mathrm{~mm}^{2}$. The dimension of

${ }^{*}$ Author for correspondence 
feed line is $6.035 \times 11 \mathrm{~mm}^{2}$. The front and back view of an antenna is shown in figure 2.1 and 2.2. In this structure the four number of slots are introduced and then cut from the ground plane. Resonant frequency depends upon the dimensions of slot as well as number of slots. In this antenna a torus is introduced on the patch and on the edge of patch triangle shape is introduced and then cut it from the patch. In table 1 the dimensions of the proposed antenna is shown.

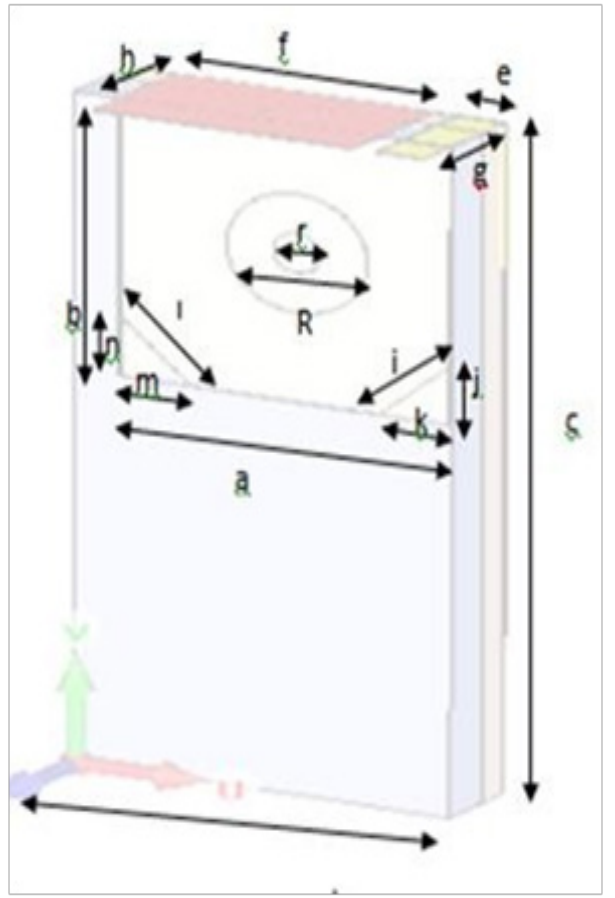

Figure 2.1 Front view of proposed antenna.

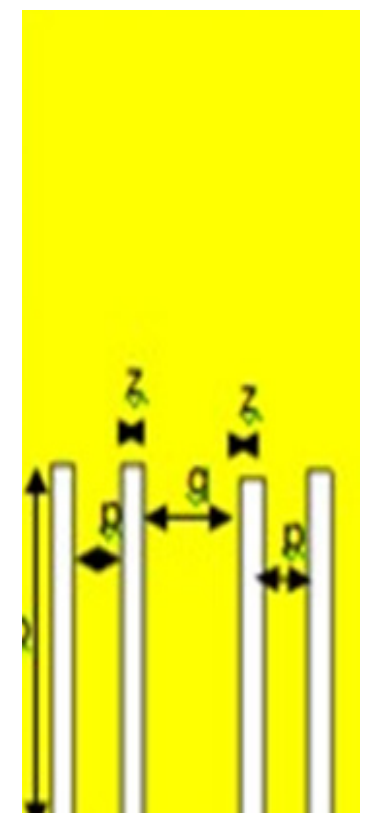

Figure 2.2. Back view of proposed antenna.
Table 1. Dimension of proposed PIFA

\begin{tabular}{|l|l|l|l|}
\hline Symbols & $\begin{array}{l}\text { Dimen } \\
\text {-sions } \\
\text { in mm }\end{array}$ & Symbols & $\begin{array}{l}\text { Dimen } \\
\text {-sions in } \\
\text { mm }\end{array}$ \\
\hline $\begin{array}{l}\text { f (width of } \\
\text { feeding plate) }\end{array}$ & 11 & $\begin{array}{l}\text { m (side of LHS } \\
\text { triangle) }\end{array}$ & 16 \\
\hline $\begin{array}{l}\text { h (length of } \\
\text { feeding plate) }\end{array}$ & 6.035 & $\begin{array}{l}\text { n (side of LHS } \\
\text { triangle) }\end{array}$ & 16 \\
\hline r (small radius) & 1 & $\begin{array}{l}\text { e (width of } \\
\text { shorting plate) }\end{array}$ & 2 \\
\hline $\begin{array}{l}\text { R (Large } \\
\text { radius) }\end{array}$ & 3 & $\begin{array}{l}\text { g (length of } \\
\text { shorting } \\
\text { plate) }\end{array}$ & 6.035 \\
\hline $\begin{array}{l}\text { i (side of RHS } \\
\text { triangle) }\end{array}$ & 4 & $\begin{array}{l}\text { c (length of } \\
\text { ground } \\
\text { plane) }\end{array}$ & 34 \\
\hline $\begin{array}{l}\mathrm{j} \text { (side of RHS } \\
\text { triangle) }\end{array}$ & 7 & $\begin{array}{l}\text { d (width of } \\
\text { ground } \\
\text { plane) }\end{array}$ & 16 \\
\hline $\begin{array}{l}\mathrm{k} \text { (side of RHS } \\
\text { triangle) }\end{array}$ & 7 & $\begin{array}{l}\text { a (width of top } \\
\text { patch) }\end{array}$ & 14 \\
\hline $\begin{array}{l}\text { l (side of LHS } \\
\text { triangle) }\end{array}$ & 15 & $\begin{array}{l}\text { b(length of top } \\
\text { patch) }\end{array}$ & 9 \\
\hline $\mathrm{z}$ (width of slot) & 1 & $\begin{array}{l}\mathrm{q}(\text { distance } \\
\text { between two } \\
\text { slots) }\end{array}$ & 4 \\
\hline $\begin{array}{l}\mathrm{p} \text { (distance } \\
\text { between two slots) }\end{array}$ & 3 & \begin{tabular}{l} 
o (length of slot) \\
\hline
\end{tabular} & 14 \\
\hline
\end{tabular}

\section{Result}

For designing and simulation CST Studio Suite 2014 software is used. The simulated frequency versus reflection coefficient of proposed antenna is shown in figure 3.1. This

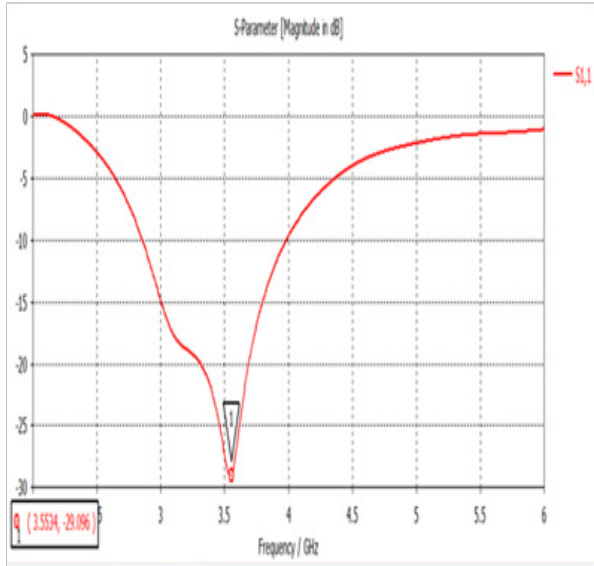

Figure 3.1. Simulated frequency versus reflection coefficient of proposed antenna. 


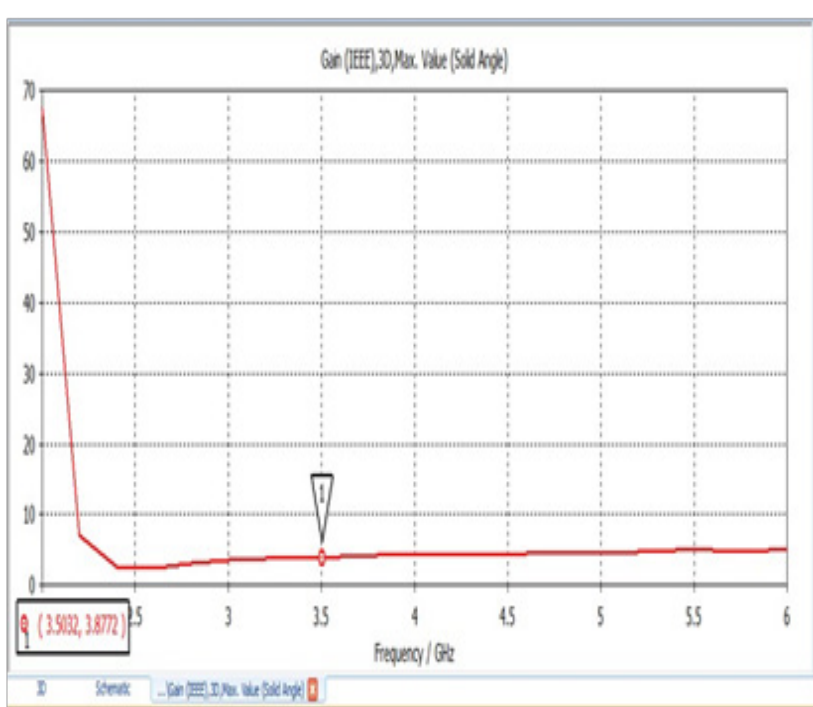

Figure 3.2. Simulated results of VSWR of proposed antenna.

Figure 3.2 depicts that at resonant frequency the value of VSWR lies between 1 to 2, which shows that the maximum power is radiated from antenna and less amount of power is reflected back.

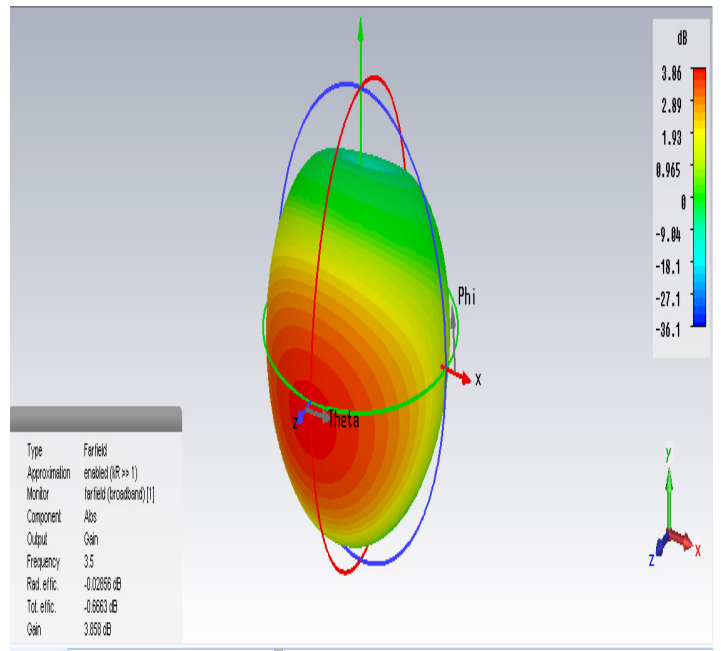

Figure3.3. Graph of peak gain of proposed antenna.

In Figure 3.3 the 3D graph of peak gain of proposed antenna is shown. Which shows that the peak gain is 3.86 over all bandwidth, which is good enough in case of 4G/5G applications.

In figure 3.4 variation of farfield directivity is shown in terms of theta angle. In this it shows that at resonant frequency, the main lobe magnitude is $3.8 \mathrm{Bi}$ and main lobe direction is 0.0 degree. The antenna radiates power in a beamwidth of 193.7 degrees.

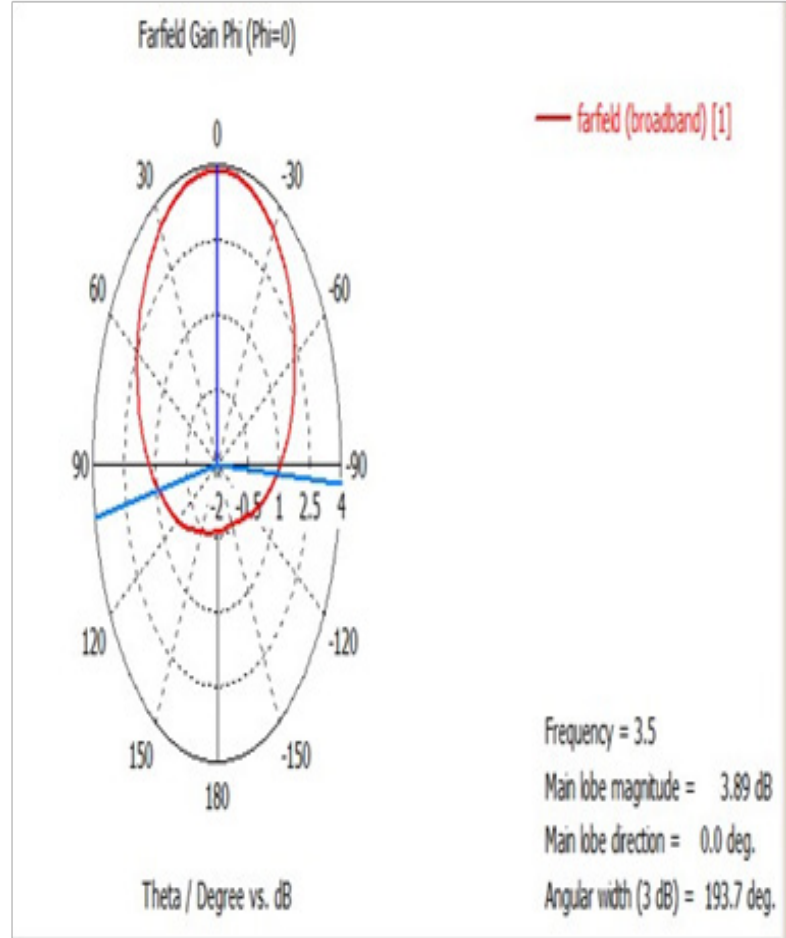

Figure 3.4. Graph of farfield directivity at phi $=0$.

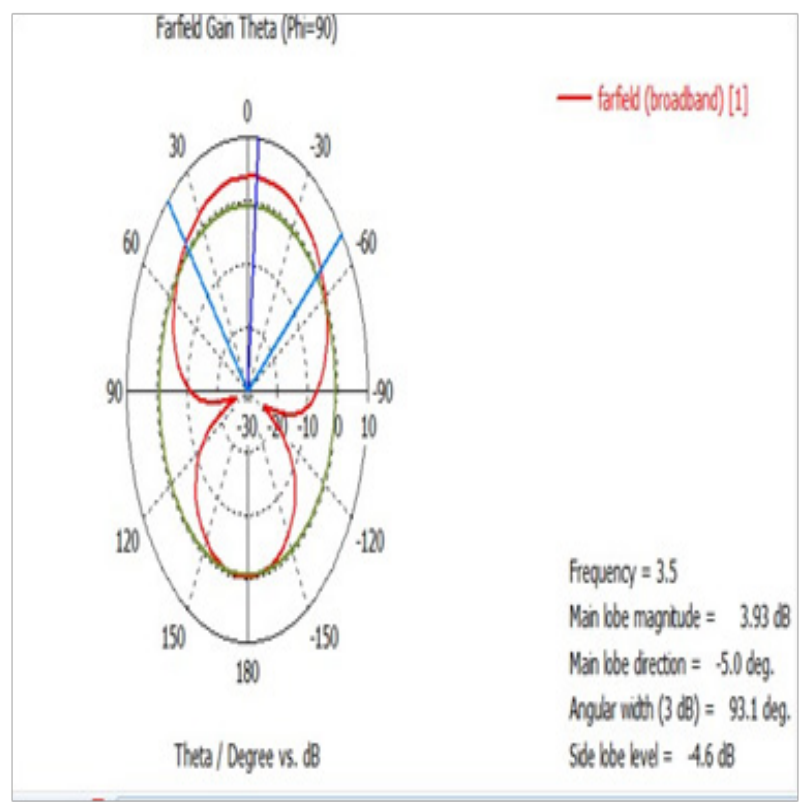

Figure 3.5. Graph of farfield directivity at phi $=90$.

In figure 3.5 variation of farfield directivity is shown in terms of theta angle. In this it shows that at resonant frequency, the main lobe magnitude is $3.93 \mathrm{~B}$ and main lobe direction is -5.0 degree. The antenna radiates power in a beamwidth of 93.1 degrees. 


\section{Conclusion}

In this paper an edge fed planar inverted $\mathrm{F}$ antenna (PIFA) for LTE high band applications is proposed. Edge feed mechanism is used in the proposed structure by which wider bandwidth is achieved. The dimension of proposed antenna is optimized using CST software and is presented in this paper. The dimension of patch, shorting plate, feeding plate are varied and optimized to get optimum results. The value of peak gain over entire bandwidth is $3.86 \mathrm{~dB}$. The proposed antenna can further modified to include other bands of LTE.

\section{References}

1. Bhatti RA, Im Y-T, Park S-O. Compact PIFA for Mobile Terminals Supporting Multiple Cellular and Non-Cellular Standards. IEEE Transaction on Antennas and Propagation. 2009; 57.

2. Chiu CY, Shum KM, Chan CH. A Tunable Via-Patch Loaded PIFA With Size Reduction. IEEE Transactions on Antennas and Propag. 2007; 55.

3. Bhatti RA, Park S-O. Hepta-Band Internal Antenna for Personal Communication Handsets. IEEE Transactions on Antennas and Propag. 2007; 55.
4. Kaur R, Surekha, Kumar N. Study of Planar Inverted-F Antenna (PIFA) for Fourth Generation Wireless Devices. International Journal of Modern Computer Science. 2016; 4:35-37.

5. Row J-S. Dual-Frequency Triangular Planar Inverted-F Antenna. IEEE Transactions on Antennas and Propag. 2005; 53.

6. Guo Y-X, Chia MYW, Chen ZN. Miniature built in multiband antenna for mobile handsets. IEEE Transactions on Antennas and Propag. 2004; 52:936-1944.

7. Li Z, Rahmat-Samii Y. Optimization of PIFA IFA combination in handset antenna design. IEEE Transactions on Antennas and Propag. 2005; 53:1770-8.

8. Nguyen V-A, Bhatti RA, Park S-O. A Simple PIFA-Based Tunable Internal Antenna for Personal Communication Handsets. IEEE Antennas and Wireless Propag Lett. 2008; 7.

9. Prabhu P, Elamaran E, Lenin Desai S. Design of self-similarity multi fractal antenna for WiMAX application. Indian Journal of Science and Technology. 2016; 9.

10. Lakshm MLSNS, Madhav BTP, Jayasree G, kumar A. Analytical study on folded-slot kotch fractal antenna. Indian Journal of Science and Technology. 2015; 8:1-6. 